\title{
SUPPLY CHAIN EXECUTIVE MONITOR FOR CONTROLLING AND FAILURE MANAGEMENT IN SUPPLY CHAINS
}

\author{
LAessig, J. ; HeINRICH, S. \& DUerR, H.
}

Abstract: Suppliers (raw part and raw material plants), manufacturers (producer, assembly plants), dispatcher (dispatching agencies, dispatching centres) and logistics services providers (forwarding agencies, Express services) are integrated in more and more complex and flexible supply chains. In terms of cost efficiency and short reaction times to customer requests, an efficient supply chain organization is the major competition factor on the global market. Existing ERP or PPS systems also integrate functions to the Supply Chain Management. Nevertheless, they still provide an insufficient scope of features and cannot integrate supply chain members with their different systems or systems without SMC functionalities into the planning and organizational processes. Many aspects of the Supply Chain Management do not offer a solution or offer only sub-optimal solutions. There is a great demand for costsaving solutions of the cross-company controlling and particularly for supply-chainglobal early detection of conflicts, as well as intelligent conflict management. In this context, problems occur due to the various interfaces of existing systems and the related high development and implementation costs. The focus of the project Controlling for Intra Logistics - Supply Chain Executive Monitor (SCEM) presented in this paper is the development of a minimal-invasive add-on system for possibly existing ERP-/PPS systems for efficient controlling and dynamic failure management of business processes in supply chains and networks on the basis of a supplier network global dynamic identification number concept.

Key words: Supply Chain Management, Controlling, Failure Management, Logistics
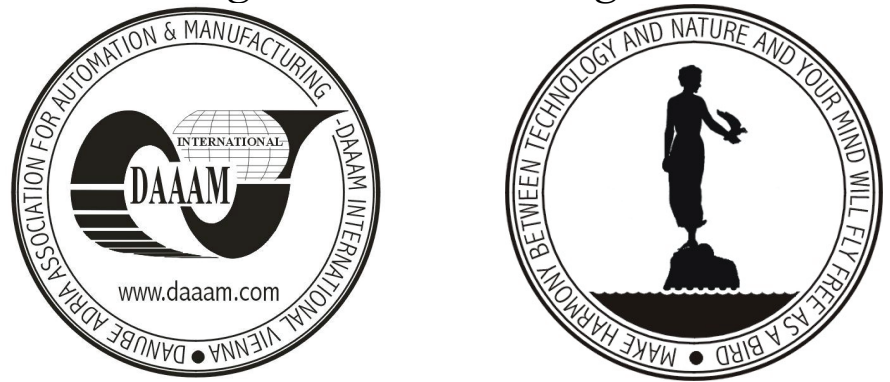

Authors' data: Dipl.-Inf. Laessig J.[oerg], Dr.-Ing. Heinrich S.[teffen], Prof. Dr.Ing. habil. Duerr H.[olger], Chemnitz University of Technology, Institute of Manufacturing and Welding Technology, Germany, joerg.laessig@mb.tuchemnitz.de, steffen.heinrich@mb.tu-chemnitz.de, holger.duerr@mb.tu-chemnitz.de

This Publication has to be referred as: Laessig, J.; Heinrich, S. \& Duerr, H. (2006). Supply Chain Executive Monitor for Controlling and Failure Management in Supply Chains, Chapter 31 in DAAAM International Scientific Book 2006, B. Katalinic (Ed.), Published by DAAAM International, ISBN 3-901509-47-X, ISSN 1726-9687, Vienna, Austria

DOI: 10.2507/daaam.scibook.2006.31 